\title{
The uncertainty challenge of contingent collaboration
}

Jennifer Claire Auer, Optimal Solutions Group, LLC

Chen-Yu Kao, School of Public Affairs, Arizona State University

Libby Hemphill, Lewis College of Human Sciences, Illinois Institute of Technology

Erik W. Johnston, Center for Policy Informatics, Arizona State University

Stephanie D. Teasley, School of Information, University of Michigan

Human Resource Management Journal, Vol 24, no 4, 2014, pages 531-547

Contingent knowledge workers will play an increasingly important role in organisational success as workers transition in and out of project-based innovation teams with more frequency. Our research finds that collaborators in the contingent, high-skill workforce face uncertainty challenges to their work that are unique from the independent, contingent professionals more often studied. The article proposes a theoretical framework of uncertainty to guide us in understanding collaborative contingent knowledge workers' work experience. Interviews with postdoctoral researchers reveal four findings about the influence of these highly uncertain work environments on collaborative contingent knowledge workers - collaboration isolation, frustrated independence, performance anxiety and internalised blame. Perhaps most concerning is that the workers internalise the negative impacts as personal failings instead of recognising them as consequences of a poorly designed work environment. This study argues for the need to manage and mitigate different sources of uncertainty to avoid creating an unnecessary burden on contingent knowledge workers, and to enable a sustainable, contingent knowledge workforce.

Contact: Dr Jennifer Claire Auer, Optimal Solutions Group, 5825 University Research Court, Suite 2800, College Park, MD 20740, USA. Email: jauer@optimalsolutionsgroup.com

Keywords: contingent workers; knowledge workers; uncertainty

\section{INTRODUCTION}

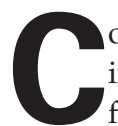

ontingent work arrangements are widespread in knowledge-intensive and innovation-related industries. For highly skilled professionals who prefer to bounce from organisation to organisation, the arrangements seem well suited. Unlike the low-skill contingent workforce, the popular image of a highly skilled contingent worker is that of a chosen 'boundaryless' career (Arthur and Rousseau, 1996), a 'protean' worker (Marvis and Hall, 1996) who is proactively self-directed, flexible and versatile, driven by personal values, and overall highly satisfied with his/her work (Marler et al., 2002). However, a number of empirical studies also reveal that contingent professionals' work experience is not without contradiction, especially as it relates to the uncertainty of contingent work arrangements (Barley, 1996; Clinton et al., 2006; Redpath et al., 2009a).

The rise of a variety of short-term collaborative work processes adds additional complexity to the work life of contingent professionals. Their work is distinctly knowledge-based, meaning that workers actively engage in the creation and application of original content rather than in routine tasks (Benson and Brown, 2007). However, unlike independent knowledge workers, the value added in collaborative innovation work is a collective attribute that requires full participation from a group. Both the process of knowledge creation and the process of 
collaboration signify different aspects of uncertainty embedded in collaborative knowledge work.

Temporary innovation teams are not new in organisations (Fiore, 2008; Lepak and Snell, 2003). What is new is that employers increasingly draw on individual contingent workers for temporary assignments, rather than create temporary teams from workers within organisations (Chesbrough, 2006; Koch et al., 2011; Kinnie and Swart, 2012). The status of being contingent compounds the uncertainty that surrounds collaboration and knowledge creation, and places the workers in a work experience about which human resource management (HRM) scholars know little.

This study asks how the heightened uncertainty found at the intersection of collaborative and contingent knowledge work influences the work experience of knowledge workers. This type of worker is defined in this study as a Collaborative Contingent Knowledge Worker $(C C K W)$. Different aspects of uncertainty serve as the theoretical framework for us to understand workers' experiences. Currently, the most recognisable workforce of this type is postdoctoral researchers (postdocs). Therefore, in this study, the postdocs' work experience is assessed and a grounded theory of uncertainty in CCKW is proposed. The goal of this study is ultimately to provide managers with important information about how to manage worker uncertainty to promote positive work experiences (Lind and Van den Bos, 2002; Thau et al., 2009).

\section{CCKWs}

\section{The contingent knowledge work continuum}

CCKWs do not fit neatly into prior typologies of contingent work. To define the CCKW population, this article pairs two continuums (Figure 1). The first continuum describes contingent work. One of the broadest and earliest definitions of contingent work was offered by the US Bureau of Labor Statistics, which defined contingent work as 'any job in which an individual does not have an explicit or implicit contract for long-term employment or one in which the minimum hours worked can vary in a nonsystematic manner' (Polivka and Nardone, 1989: 11). A variety of working arrangements, however, can fall under the umbrella of

Figure 1 Types of contingent knowledge work

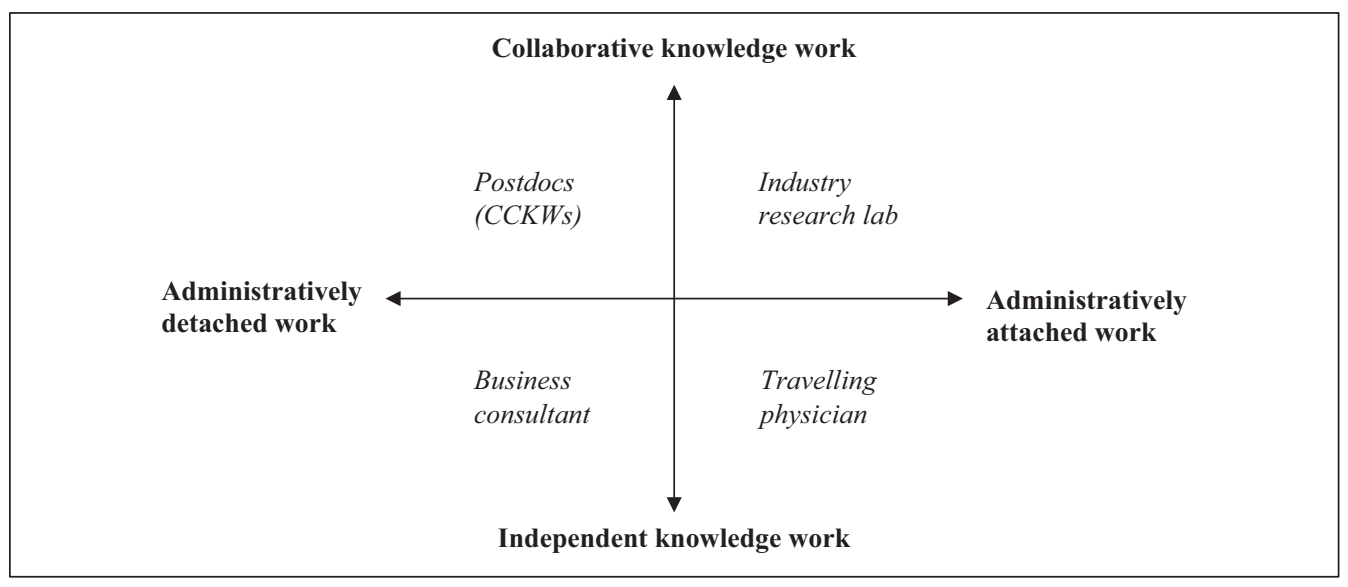


contingent work. Different empirical studies may sample different populations, lead to inconsistent results and cause difficulty in theory building (Connelly and Gallagher, 2004; Ashford et al., 2007; Osnowitz, 2010). Thus, definitions and typologies have proliferated over the years, partly in an attempt to better interpret the variety of outcomes observed in research on contingent workers (Connelly and Gallagher, 2004; Ashford et al., 2007).

Cappelli and Keller (2013) proposed a holistic classification system based on the organisation's administrative control over employees, a classification property that allows a clear distinction among different work arrangements, and one that persists over time despite changes in the environment. This property has been termed as 'administrative attachment' since Pfeffer and Baron (1988). Accordingly, this article uses 'administrative attachment' to describe contingent work (Figure 1). Instead of going into the details of various contingent work categories, this continuum intends to demonstrate variation in the degree of administrative control, such as work supervision. The left end shows weak administrative control and the type of work is labelled as 'administratively detached work', while the right end demonstrates strong administrative control and is labelled as 'administratively attached work'.

\section{The collaborative knowledge work continuum}

A number of high-skill occupations are subject to contingent status, including business consultants (Donnelly, 2008), travelling physicians (Alonzo and Simon, 2008), itinerant IT experts (Barley and Kunda, 2006) and a variety of portfolio workers (e.g. freelance writers) (Mallon and Duberley, 2000; Clinton et al., 2006; Redpath et al., 2009a). For the most part, previous studies have focused on independent contingent knowledge work, but rising interest in innovation highlights the importance of collaboration to generate the knowledge necessary for competitive advantage (Bozeman and Corley, 2004; Cummings and Kiesler, 2007; Fiore, 2008). The present study does not tackle the nuances of collaboration, but it makes the important distinction between independent contingent professions and collaborative contingent professions. Consequently, the second continuum describes degrees of collaboration in high-skill knowledge work (Figure 1). The upper end represents collaborative contingent knowledge work, which produces co-creation through highly integrated teamwork, while the other end of this continuum represents 'independent knowledge work', such as the lone consultant who extracts information from clients to deliver the product.

\section{Defining CCKWs}

What results from the intersection of these two continuums are four types of contingent knowledge workers. Dimensions of work can vary within professions as much as between them, but as shown in Figure 1, the industry research lab, travelling physician and business consultant represent three types of knowledge workers studied in HRM (Alonzo and Simon, 2008; Donnelly, 2008; Fiore, 2008). The upper left-hand quadrant is what this article refers to as the fourth type of knowledge workers - the collaborative contingent knowledge workers (CCKWs), a new type of knowledge professional whose work takes place in the contingent and collaborative intersection. Temporary academic positions, such as postdocs (McAlpine, 2010), and some highly collaborative consultants (Clinton et al., 2006) are current examples of CCKWs. Although the continuums described could be further and more precisely elaborated, they serve the important purpose of highlighting a burgeoning labour force that is uniquely affected by uncertainty. We expect it to continue to expand as open-source innovation platforms, crowd-sourcing and other project-based work environments grow (Malone, 2004). 


\section{Current example of CCKWs: postdocs}

The traditional view of the postdoc period is that of a stepping stone to a permanent position, but postdocs increasingly reflect the protean career perspective because a sizable subgroup jumps from one appointment to the next, or from a postdoc position to a career outside academia (Akerlind, 2005; Bonetta, 2010). Previous research on postdocs is sparse and is mostly descriptions of postdocs' discontent with the current system. For example, previous studies indicate that postdocs are concerned about the quality of mentoring (Singer, 2004; Davis, 2006; Scaffidi and Berman, 2011), career structure and prospects, nurturing environment (Davis, 2006; Aschwanden, 2006; Scaffidi and Berman, 2011), networking opportunities, professional development training (Bonetta, 2010; Lee et al., 2010), benefits, and disparities in stipends (Davis, 2006; Aschwanden, 2006). These studies offered limited understanding of postdocs' experiences, except their experience of job insecurity (Scaffidi and Berman, 2011). Moreover, the uncertainty that uniquely affects this type of workforce has not been examined. In the current study, we propose a theoretical framework of uncertainty to guide us in understanding CCKWs' work experience.

\section{THEORETICAL FRAMEWORK}

\section{Previous research on contingent knowledge workers: uncertainty in contingent work}

Previous studies on contingent knowledge workers are plentiful. However, research focusing on the contingent professional's experience stemming from the contingent nature of work is limited. Some studies indicate that contingent professionals experienced job insecurity (McAlpine, 2010), social isolation and uncertainty (Clinton et al., 2006); they highlight the detachment characteristics of the work, including ongoing relocation (McAlpine, 2010), loss of organisational roles, and unmet belonging and affiliation needs (Mallon and Duberley, 2000). Moreover, Barley's (1996) seminal ethnography on contingent professionals found that the most consistent sentiment expressed was uncertainty about the work. A qualitative study also indicates that coping with uncertainty is a major theme identified from the interview data of contingent professions, and that uncertainty can have direct influences on organisational outcomes, such as loyalty, commitment and productivity (Redpath et al., 2009b).

\section{Uncertainty in collaborative knowledge work}

To the extent that previous research has highlighted the uncertainty experience of contingent professionals, it has focused on the uncertainty caused by contingent factors, such as temporary positions or detachment from the organisation. However, as Barley (1996) suggests, uncertainty is nuanced and its sources varied. For CCKWs, the contingent nature of the work is indeed an important dimension of uncertainty, but it is just one source. Uncertainty caused by factors related to collaboration and knowledge creation also needs to be taken into account. The current research aims to cull broad sources of uncertainty in collaborative knowledge work and to understand how these different sources of uncertainty shape workers' affective experience. The list is not exhaustive or definitive across all knowledge work, but it begins to systematically unpack the uncertainty that stems from the new forms of work arrangements, so that its impact on the daily experience of CCKWs can be disentangled.

Strategic uncertainty Strategic uncertainty stems from the need for a collaborative knowledge worker to coordinate his/her action with multiple, interdependent individuals to share and create knowledge (Jackson and Hong, 2008). The term strategic uncertainty comes from studies 
of common pool (natural) resources where it is used to distinguish between uncertainty about how individuals will extract from a common resource and uncertainty about how the underlying environmental system replenishes itself (Gangadharan and Nemes, 2009): 'Environmental uncertainty refers to environmental variables that determine which group action is best, while [strategic] uncertainty centres on how other group members will respond ... The problem that is raised by the environmental uncertainty is the problem of optimality or efficiency, while the problem raised by [strategic] uncertainty is (...) coordination' (Messick et al., 1988: 678-679).

Strategic uncertainty is an inherent property of interdependent group work. Collaboration participants run the risk that others will act self-interestedly in exchange of knowledge, exploiting the group by limiting the amount of time and effort they contribute (i.e. free-riding), while reaping the benefit of the collective outcome (e.g. an invention, an innovation in service or a scientific publication) (Tyler and Lind, 1992). In weighing the costs and benefits of participation in a collaborative project and determining whether or how much creative effort to invest, CCKWs face uncertainty about their team members' behaviour. The problem of group coordination has been identified in the context of collaboration among groups of researchers (Cummings and Kiesler, 2007), groups of consultants (Heusinkveld and Benders, 2005) and other situations of group innovation.

Systemic uncertainty Systemic uncertainty occurs because of the process of knowledge creation itself, which usually involves applying intangible, tacit information that is hard to document in handbooks (Alvesson, 2001). As the science and technology studies literature indicates, this uncertainty is systemic to the whole process of innovation (Lane and Maxfield, 2005). Furthermore, it goes beyond the search for facts and into creating the multiple frames under which 'facts' could be understood or collected, which makes knowledge work both technical and creative. In group situations, it is related to the need for shared mental models to improve performance (Mathieu et al., 2005). Systemic uncertainty is especially problematic for early career knowledge workers, as they become accustomed to the craft aspects of their science (Delamont and Atkinson, 2001). Yet difficulties in documenting competence given systemic uncertainty were also found in computer consultants (Alvesson, 2001) and other mature technicians across a number of team-based, high-skill fields (Barley and Kunda, 2006).

Reward uncertainty Organisational behaviour research has historically focused on the type of uncertainty defined by a lack of the 'information needed to achieve a given level of performance' (Binyamin and Carmeli, 2010: 1005). Collaborative knowledge workers face reward uncertainty about performance and promotion that are unique from other work environments. For knowledge work in engineering, biosciences and other industries that employ technicians, authority and expertise often do not coincide, which complicates ownership among collaborators with different roles (Barley, 1996). Funding mechanisms in research and development grants (Singer, 2004; Fiore, 2008), and in fields like architecture (Cohen et al., 2005) and product development consultancy (Heusinkveld and Benders, 2005), obfuscate who can confer performance rewards because project funding is obtained by individuals or a small team responding to clients. The intangible intellectual assets of knowledge work are also simply more difficult to objectively evaluate for the quality or impact (Alvesson, 2001). Lack of clear and consistent HR policies to mitigate these issues has been shown to reduce the psychological capacities necessary for innovation by increasing worker uncertainty (Binyamin and Carmeli, 2010). Reward uncertainty is endemic to collaborative knowledge work. 


\section{METHODS}

\section{Data source}

Reported here are data from interviews with 30 postdocs, collected as part of the US National Science Foundation's (NSF) Virtual Organization Sociotechnical Systems programme. They were interviewed independently about their experiences in 1 hour; semi-structured interviews were conducted face to face or by Skype. Interviews were audio-recorded and then transcribed. The respondents are from four large- and medium-sized universities and three research institutions. Most of the respondents were participating in teams that collaborate with researchers in other parts of the US $(n=25)$ as well as overseas $(n=5)$. Just one postdoc was stationed at a university in Europe. They work in a number of academic areas, including the social sciences and humanities, but they are primarily in the natural sciences and medicine, such as subfields in biology.

Participating postdocs were those who responded to an open invitation that they received from us as a member of a postdoc association listserv, as an NSF-funded distributed research team or through word of mouth as awareness of our study spread among the postdoc community. Interviewees received $\$ 20$ for their time. The postdocs themselves are primarily US born, but about a third come from countries such as India, Germany and China, and work in US institutions. We interviewed both men $(n=13)$ and women $(n=17)$. We did not collect data on the participant's age, but because some participants were in their second or third postdoc position, the average age is likely higher than studies of 'new' postdocs. Interviews were conducted in 2010 and 2011.

\section{Data analysis}

The interview data were analysed using the grounded theory approach (Glaser and Strauss, 1967; Charmaz, 2003). In grounded theory, the researcher starts by being open to what can be learned from participants' experiences, and then refines the analytic categories that emerge from the data based on (a) relevant literature and (b) returning to the qualitative data collected. In an iterative and reflexive process, the researcher arrives at an empirical understanding of the case and theorises relevant propositions about a social or psychological process. This approach has been used in the context of HRM for a grounded understanding of team-based work (Francis, 2003) and innovation (Swart and Kinnie, 2003), among other topics. In this research, the significant categories were selected both for their frequency and thus descriptiveness of the postdocs experience, and then were refined into four themes that relate the affective experience to the uncertainty framework we identified above. The results reported below are not meant to characterise the study findings comprehensively but are to inform the understanding of our research framework. Pseudonyms are used to protect identity.

\section{RESULTS}

Working within the uncertainty framework introduced earlier, our data revealed four themes. For each theme, quotes and observations from the interviews are presented that demonstrate the negative social-psychological impact of uncertainty on CCKWs: collaboration isolation, frustrated independence, performance anxiety and internalised blame.

\section{Collaboration isolation under contingent and strategic uncertainty}

Given the rhetoric of innovation and interdisciplinary research, it seems natural to expect postdocs to engage in a significant amount of interaction with collaborating colleagues. The 
frequency with which postdocs reported feeling isolated was, therefore, a disheartening irony of the postdoc experience. Emotionally, some felt isolated from their research team, although there were other staff on site with whom they interacted formally and informally. Physically, two postdocs were completely isolated, with no students, administrative staff or would-be mentor on site. Tara was one of the postdocs in this unfortunate situation. Not knowing how other universities handled new team members, she lamented the lack of transition services available to her and the period of 'intense depression' that followed her arrival when her sole collaborator left a week later due to a family emergency. Melanie was another interviewee who was physically isolated from her new colleagues. She had this to say about her experience: "Well, what I feel like is they don't know me because no one's working with me, no one's talking to me and so it's kind of, I have this fear that this could just seem like a lost year". She turned to cold-calling potential collaborators because her supervisor was available only by Skype, when he was available, and those in her hallway mostly worked from home.

Emotional isolation from collaborators was experienced jointly and independently of physical isolation. Postdocs were fairly resourceful in identifying collaborators outside their lab when appropriate or necessary, but unsuccessful collaboration with a supervisor - typically the principal investigator (PI) of the project - weighed on them particularly heavily. They described it as feeling forgotten, in limbo and left on their own to succeed. Virtual communication was cited by just one participant as a disincentive for her collaborating team to connect once she relocated to a lab overseas. Others reported that their feelings of isolation had more to do with permanent staff who held negative perceptions of them. For example, Adesh said he felt that collaboration was stifled by teammates' fear that their ideas would be stolen or 'scooped'. Several postdocs mentioned the issue of competition with PI as problematic for collaboration, both with young lab leaders who are still making their name and with experienced leaders who, according to one interviewee, get grants based on their name and farm out the work while they "go on speaking tours and drink coffee".

Absent or competitive collaborators reduced team commitment from the postdocs themselves: as Tim commented, "there is plenty of science to be done elsewhere". By contrast, in research teams that met weekly to discuss and present their work, postdocs typically reported friendlier and more frequent research collaborations. When asked what makes a good lab, respondents universally discussed the need for friendly, supportive collaborators. Because several interviewees were in their second or even third postdoc position, they specifically compared the problem of combative teams with their earlier, more positive experiences of collaboration.

\section{Frustrated independence under contingent and systemic uncertainty}

Temporary knowledge workers must concurrently navigate the discretion and responsibility required to create a personally and professionally satisfying portfolio across projects (Clinton et al., 2006). Postdocs reported that their attempts at independence were frustrated by external forces, and also that they felt frustrated by the unclear level of independence that was required of them. In comparing her postdoc and graduate school experiences, Lindsey summarised the pressure she felt by explaining that in graduate school, work is partly carved out for students and failure can be attributed elsewhere, whereas "now, you are supposed to define your own project and you are supposed to make it work. You're building what you are going to work on because I can't be known for what my PI works on". Several postdocs remarked on the frustration that comes with being a "completely independent researcher", managing projects, publications and money. There is a high level of stress figuring out how to do "this kind of work", and collaboration isolation makes it all the more difficult. Parvati concluded that it prevents "scientific thinking", noting that: 
"[W]e definitely have a lot of interpretation to do because sometimes, very new to the field, it takes a while for me to interpret what kind of results [I] have in hand. / / As a group if you sit together and jot down what kind of aim you have for the following week / / I think that really helps to take a project ahead in a very different way than an individual can do at its own level". ${ }^{1}$

To another postdoc, initiating his collaborative project felt like a "strange way" of approaching science:

"It's not like I started out saying, you know, I am interested in studying climate change, and this particular aspect of climate change, and to do that well I need this person, this person and this person, you know. It's a little bit more like ... I'm trying to understand what the interests are out there and then to get people onboard with what you want to do" (Colin).

Meanwhile, a third postdoc interviewee, Todd, argued that frustration could be reduced if an initial period of dependence was followed by a period of greater autonomy, where postdocs can eventually be trusted to assemble a "coherent scientific story" from data, new medical images in his case and not simply execute the aims of the lab director.

Postdocs sought mentorship, not supervision, to build their independence. But the initial structure and guidance that Todd described appears crucial for postdocs to find their scientific identity. For instance, one postdoc struggled to understand the negative comments of a journal editor she had received: "I think I might be more of a kind of applied practical person than a theory person but I don't know. So I'm trying to figure [it] out, where do I belong, I don't know". This same postdoc worried about her expertise: "I'm not getting enough guidance from my direct supervisor. So, I don't feel I'm learning what I'm supposed to learn, so I'm not becoming an expert in the area". Some postdocs also commented on the positive side of their research independence, saying they felt more in control of their destiny, or that it offered them a chance to learn how they work, what they are good at and what motivates them. Yet, for the most part, the experience of CCKW does not appear to strike the right balance between independence and guidance, as this interviewee reflects: "If I were going to describe what [it] was [like] at my postdoc experience, yeah. Really like flailing. I mean anxious, uncertain, confused, like really wanting guidance".

\section{Performance anxiety under contingent and reward uncertainty}

"I'm never quite sure if I'm meeting the normal expectations of a postdoc. But at the same token, I understand by having to work that way [independently] it would [be] more beneficial if I had a clear goal set in mind to then achieve that goal. // So I guess, it's professionally good to not have external expectations. However, it would help to know whether or not I'm meeting professional expectations" (Audrey).

A third finding of the postdoc work experience is uncertainty over performance standards that, essentially, do not exist. Along with a lack of guidance on the more tacit aspects of innovation, almost no postdocs had a formal evaluation process for their performance. Audrey's desire for clearer work expectations is echoed by Valerie, Sofia, Brian and Maria. Regarding a supervisor's standard request to "get it done as soon as you can, get it done promptly", Valerie told us that deadlines would be a day-to-day work life improvement, noting after a brief pause, "I don't know what those dates are // I just sit there re-working something until I can't look at it anymore". Unwritten expectations, as one interviewee called them, have very real 
consequences for temporary workers. Sofia explained that when they are not met and your contract is up after the year "somebody just says, 'Well, unfortunately we don't have any more funding'. Which is sometimes not true because you know that your PI has a lot of funds".

Creation and ownership of knowledge work, such as a publication, grant, patent rights or even a design concept, are the most significant end products in the academia, but the often-long turnaround times make them inadequate metrics for performance improvement in contingent arrangements. The importance of these external performance indicators to professional success, coupled with little formal review, led postdocs to describe a vague culture of unachievable expectations.

"[B]asically, I'm just supposed to be a research power house. I need to build my portfolio, get papers out, build the research program that I will then start a lab on, and that's ... that's just sort of ... there's no ... there's no book that says you have to do that but that's sort of how it is. It's a culture. // [Y]ou can never ... well it's all passive-aggressive and you can never fulfil what the expectation is, you just can't; physically, mentally, you cannot" (Brian).

Maria described the culture of expectations as nerve-wrecking and stressful, reflecting: "I guess no one sees this but once you graduate // it's kind of like an unofficial pressure that you know you need to do things better and kind of faster than what you did in grad school because now you have the doctorate so they will be expecting more from you".

Practical career guidance appears to be a low priority for supervisors. For instance, one postdoc expressed sadness when asked about her relationship with her mentor saying, "[My mentor and I have] very nice and friendly interaction, but sadly without much discussion of my goals and expectations for this position". Another postdoc reported that his "mentor is hands off and while in contact, not concerned with my career advancement. He is more concerned [with having] a warm body to conduct research". This latter perspective on career advancement adds context to why tension builds between the research independence and collaboration necessary for work success. Negotiating authorship of a publication, ownership of a data set or one's contribution to other performance outcomes on which these knowledge professions are evaluated was a clear source of stress. When asked about authorship, interviewees said things like: "I don't really understand // [but] the way it seems to be going is if you're first author, you pretty much write the entire article and then everybody else may just review it once or twice and then their names are put on it". In reference to patents, Bill said: "I mean basically, if you're a postdoc and you work in a lab, everything that you do is really given credit to the professor, the lab boss, and they demand ownership". When supervisors cross the ethical line with claiming credit, feeling anxious is clearly an understatement. Sofia described it like working in a jungle when a lab boss pits postdocs against one another in the race for new discoveries.

\section{Internalised blame}

The exceedingly nebulous work, vague performance measures and lack of positive interactions were acknowledged by postdocs, but they were internalised as personal failings instead of a consequence of their work arrangement. For instance, Melanie said, "I have this fear that this intense independence is just going to translate into failure. I don't know. That's ... I don't know it's just a bad feeling". Kai echoed her comments saying, "[postdocs] regard this as personal failure rather than failure of, lets say, the system. And that related to my feelings pretty well".

Rather than attribute stress to collaborating virtually or always looking for that next job, postdocs often saw these as 'unsolvable' externalities of CCKW, making their stress a signal that 
they could not handle their professional situation. For example, a postdoc named Leslie resolved that she could not compete and would never be "a superstar or the favorite", and was just glad no one made her feel bad about it. In writing her own reference letter on behalf of her supervisor, another postdoc concluded that the difficulty of summarising her potential for success was that she did not know if she had any potential for success. Particularly disheartening was the fact that more than one postdoc noted they had gone into the position thinking it was a time to build their confidence as an independent researcher. Then, in the end, the opposite occurred. When asked for three adjectives to describe his postdoc experience, Stefan replied: "The first thing coming to mind is exhausting. Second, would be frustrating. And the third would probably be hopeless".

\section{DISCUSSION}

\section{Uncertainty and negative work experience of CCKWs}

This research is to understand how the uncertainty found at the intersection of collaborative and contingent knowledge work influences the work experience of knowledge workers. Using the method of grounded theory building, a reflexive process to analyse the interview data and to refine the themes, we have developed a systematic understanding of the relationship between the sources of uncertainty and the negative work experiences of CCKWs. Four theoretical propositions are derived based on our findings and are discussed as follows.

Proposition 1: Strategic uncertainty, worsened by and along with contingent factors, shapes the collaboration isolation experience of CCKWs.

In our analysis, several contingent uncertainty factors strongly worsen the strategic uncertainty found in the team collaboration context, and along with strategic uncertainty shape the collaboration isolation experience of CCKWs. Although this article highlights administrative attachment in contingent work, it is clear that other types of attachment between workers and organisations are intertwined, and as noted by Pfeffer and Baron (1988) could be challenging for researchers to tease apart empirically. Specifically, physical attachment is based on the degree of physical proximity and temporal attachment is based on the expected duration of employment (Pfeffer and Baron, 1988). Some contingent workers may be physically detached from their organisations, namely working at home or at different locations, and communicating with their colleagues and supervisors via virtual communication technologies. On the other hand, some contingent workers may be more temporally detached from organisations, with shorter contracts and term positions, while other may have longer work relation and be more temporally attached. The purpose here is not to differentiate the impacts of these three different attachments, but to illustrate how they interact and holistically represent the work system faced by postdocs.

Collaborative knowledge work often takes place in project teams. How to better manage and lead project teams to avoid the strategic uncertainty in collaboration (Kniffin and Wilson, 2005) and to enhance team performance (Gersick, 1988; Senior, 1997) have been topics for team and group management studies. However, the well-regarded team development and management theories and practices grounded in traditional organisations (Tuckman and Jensen, 1977; Feldman, 1984; Parker, 1990) may be ill-fitted to contingent work situations. Foremost, because CCKWs are administratively detached from the organisation, here the university academic units, it offers limited or even no transition services and guidance to newly arrived team members, such as orientation and socialisation processes that organisations typically offer to newcomers (Ashforth and Saks, 1996). This lack of appropriate HR supports based on 
organisational command and control functions makes team formation difficult at the very beginning. The problem of physical detachment from supervisors or colleagues seems to exacerbate the difficulty in team formation and collaboration. Furthermore, the limited employment duration of contingent workers is usually an unfavourable condition for group norm development and team role-building, both of which have been shown to be important for team members' commitment to their teamwork and crucial for team performance (Belbin, 1981, 1993; Feldman, 1984; Senior, 1997). Strategic uncertainty in collaboration could be overcome through a cyclical process of trust building, commitment and a shared understanding of what the group can collectively achieve, a process facilitated by face-to-face interaction at the start, and intermediate outcomes throughout (Ansell and Gash, 2007). However, being administratively, physically or temporally detached, this process seems to be hard to realise. The contingent factors put team collaboration in a detrimental position and worsen the strategic uncertainty facing CCKWs.

Even though studies are exploring the challenge of virtual team management (Lee, 2014), the challenge for CCKW team management is even more complicated because team members are usually in different employment arrangements. As the interviewees expressed, permanent employees often hold negative perceptions of CCKWs and collaboration is often stifled by teammates' distrust. Coupled with the detachments, team collaboration thus becomes isolation. Previous studies on contingent workers have accumulated considerable understanding of standard workers' resentment and negativity towards contingent workers (Davis-Blake et al., 2003; George, 2003; Broschak and Davis-Blake, 2006; Ashford et al., 2007), and have indicated that employees' perceived fairness plays an important role. A significant challenge for future research and practice is to determine how to manage team interfacing to enhance contingent collaboration experiences.

Proposition 2: Systemic uncertainty, worsened by and along with contingent factors, shapes the frustrated independence experience of CCKWs.

Systemic uncertainty occurs in the process of knowledge creation, which usually involves the use of intangible tacit knowledge and could be regarded as art, needing time and experience to master. Traditionally, in knowledge and innovation organisations, the frustrated independence caused by systemic uncertainty could be eased by strong organisational identity, which can act as a buffer against the ambiguity in valuing one's innovation ability and ease the knowledge worker's struggle for self-esteem (Alvesson, 2001; Heusinkveld and Benders, 2005; Brown, 2007). However, organisation detachment imposes a significant challenge for constructing organisational identity. Studies show that contingent workers experience the issue of liminality (Garsten, 1999; Czarniawska and Mazza, 2003; Ashford et al., 2007; Ellis and Ybema, 2010; Beech, 2011). According to Noble and Walker (1997), liminality 'significantly disrupt[s] one's internal sense of self or place within a social system' (p. 31). In organisational settings, liminality usually refers to the position of ambiguity and uncertainty, the constantly changing circumstances, the instabilities in social context, and the multiplicity of meanings (Beech, 2011). Being liminal, in-between-ness, makes the construction of organisational identity difficult and this buffer disappears, leading to CCKWs' independence frustration when facing systemic uncertainty. However, it is noteworthy that the CCKWs in our study seem to seek building their scientific and professional identity more than building organisational identity. Their frustration comes more from the uncertain expectations in their professional field rather than from the uncertainty in their contributions to the organisation. Consequently, what they need seems to be the construction of professional identity and professional mentorship rather 
than organisational guidance or training (Sampson and St. James, 2012). Future studies would need to address how to effectively construct CCKWs' professional identity and to build effective professional mentorship programmes.

Proposition 3: Reward uncertainty, worsened by and along with contingent factors, shapes the performance anxiety experience of CCKWs.

In this analysis, the long turnaround time of academic publication indicates a lack of short-term evaluation for performance improvement. Vague professional expectations hardly make performance benchmarks clear. CCKWs can feel more anxious about their performance and progress. The reward uncertainty is excerbated by contingent factors. Administrative detachment is indicative of ad hoc, informal, or no performance evaluation; undocumented performance rewards; and the lack of a clear reward system for advancement. Rather, CCKWs need to negotiate their performance reward with their supervisors (Heusinkveld and Benders, 2005). Without the key organisational mechanisms of formalisation and structuralisation (Lind and Van den Bos, 2002), this uncertainty goes unchecked and performance anxiety inevitably mounts. Moreover, the advancement and promotion opportunities within an organisation have been widely recongnised as an important reward sytem to motivate employees but seem to have lost their function in CCKW. The administrative and temporal detachments, nevertheless, lead to a lack of clear career advancement supports and opportunities for promotion. Future studies would need to further address the challenges of how to formalise the reward system in CCKW arrangement and how to effectively motivate employees who sit partially outside of the traditional organisation boundaries.

Proposition 4: The negative experiences shaped by aspects of uncertainty are internalised as personal failure rather than the problems of the work arrangements, and this internalised blame could have potential influences on CCKWs' quality of employment.

In our analysis, the interviewees are prone to attribute these negative experiences to their personal failure in handling their professions. Despite criticising the current system, they generally view it as an unsolvable fact. This internalised blame could be potentially detrimental to employees' self-esteem, as descriptions like personal failure, lack of potential, and hopeless indicate. This finding could explain the negative relationship between work status and mental health (Guest, 2004). More strikingly, they constantly link the internalised blame to negative feeling towards working as CCKWs as a whole, implying the potential negative influences on CCKWs' overall job satisfaction (Maynard et al., 2006). Self-esteem, depressed mood and overall job satisfaction are important affective facets of the quality of employment (Quinn and Shepard, 1974). This study highlights the urgent need for future research to figure out how to address the systematic and structural problems embedded in CCKW to avoid further dampening the long-term viability of the high-skill contingent workforce.

\section{Theoretical contributions and implications for future research}

This study contributes to understanding the burgeoning workforce of CCKWs by proposing a typology that identifies them more explicitly. Further research should further refine this typology and examine its implications to the work classification system in the new economy (Cappelli and Keller, 2013). Second, unlike previous descriptive studies, this study focuses on the mechanisms leading to CCKWs' negative experiences. This study argues for a grounded theory of uncertainty in CCKWs, which offers a systematic way to explain, to manage and to improve CCKWs' work experiences. Future studies should further examine this framework. 
Third, previous studies on CCKWs' affective reactions towards their work arrangements are sparse. This article adds to our understanding in this regard. Fourth, this study contributes to our understanding of CCKWs' feeling towards their teammates under non-standard work arrangements, while previous studies emphasized the standard worker's perception of contingent workers (Ashford et al., 2007). Our findings could also have implications for future studies on group dynamics and team management in terms of how to manage the interfaces among workers under different work arrangements. Fifth, the findings of this study suggest the importance of breaking traditional organisational boundaries and instead emphasising how teams and professions function. A number of organisational theories should be revisited in this light, such as motivation, socialisation, identity and structuralisation. By doing so, studies on the new workforce could contribute more to the theoretical underpinnings of organisation behaviour.

\section{Managerial implications}

This study argues for commensurate attention to the unique management challenges of CCKWs. The findings suggest that team leadership and team management could replace division and unit management to more effectively monitor and reduce worker uncertainty. A more task-driven and professional-positioning orientation of team building could possibly replace the traditional group forming strategies (Lee, 2014). Managing the blending of workers highlights the importance of re-examining relationship management, equity theory (Adams, 1965) and expectancy theory (Vroom, 1964). This study would also argue for the importance of professional associations and labour market intermediaries (Bonet et al., 2013), within which many traditional organisation functions as we discussed previously could all be built accordingly. Many of these functions could also complement the functions of team leadership and team management, and deserve further exploration and development. For example, effective long-term mentorship programmes could be built through professional association, as a complement to the deficiency of short-term mentorship relations in project teams. Finally, it is important to note that although urgent HR and management supports are needed, CCKWs should also position themselves more as self-employed and be more responsible for building their own professional identity and for their own career advancement, and actively seeking support instead of passively relying on support to be offered through traditional organisation command and control functions.

\section{CONCLUSION}

Overall, this study contributes to the literature examining the employment and management of a burgeoning new workforce, whose work takes place across organisational boundaries and relies on a significant amount of knowledge team collaboration. This study proposes a grounded theory of uncertainty in CCKWs, from which different sources of uncertainty embedded in contingent work arrangements, collaboration and knowledge creation are disentangled, and how and why they shape workers' negative work experiences are understood. Feeling isolated, frustrated and anxious are consequences of a poorly designed system. Attributing these consequences to personal failure and the resultant hopelessness are disheartening outcomes and are counterproductive to the success of workers and organisations. Given the growing trends in hiring CCKWs, it is urgent that scholars and practitioners address systemic problems to improve the work experience for CCKWs and ultimately to ensure the long-term viability and prosperity of the high-skill workforce. 


\section{Acknowledgement}

This research is funded by NSF grants 0838206 and 0838295.

\section{Note}

1. The double backslash $(/ /)$ represents interview text omitted due to quote length.

\section{REFERENCES}

Adams, J.S. (1965). 'Inequity in social exchange', in L. Berkowitz (ed.), Advances in Experimental Social Psychology, Vol. 2, New York: Academic Press.

Akerlind, G.S. (2005). 'Postdoctoral researchers: roles, functions and career prospects'. Higher Education Research and Development, 24: 1, 21-40.

Alonzo, A.A. and Simon, A.B. (2008). 'Have stethoscope, will travel: contingent employment among physician health care providers in the United States'. Work, Employment and Society, 22: 4, 635-654.

Alvesson, M. (2001). 'Knowledge work: ambiguity, image and identity'. Human Relations, 54: 7, 863-886.

Ansell, C. and Gash, A. (2007). 'Collaborative governance in theory and practice'. Journal of Public Administration Research and Theory, 18: 4, 543-571.

Arthur, M.B. and Rousseau, D.M. (1996). The Boundaryless Career: A New Employment Principle for a New Organizational Era, New York: Oxford University Press.

Aschwanden, C. (2006). 'Professionalizing the postdoctoral experience'. Cell, 124: 3, 445-447.

Ashford, S., George, E. and Blatt, R. (2007). 'Old assumptions, new work: the opportunities and challenges of research on nonstandard employment'. Academy of Management Annals, 1: 1, 65-117.

Ashforth, B. and Saks, A. (1996). 'Socialization tactics: longitudinal effects on newcomer adjustment'. Academy of Management Journal, 39: 1, 149-178.

Barley, S.R. (1996). 'Technicians in the workplace: ethnographic evidence for bringing work into studies organization'. Administrative Science Quarterly, 41: 3, 404-441.

Barley, S.R. and Kunda, G. (2006). 'Contracting: a new form of professional practice'. Academy of Management Perspectives, 20: 1, 45-66.

Beech, N. (2011). 'Liminality and the practices of identity reconstruction'. Human Relations, 64: 2, 285-302.

Belbin, R.M. (1981). Management Teams: Why They Succeed or Fail, London: Heinemann.

Belbin, R.M. (1993). Team Roles at Work, Oxford: Butterworth-Heinemann.

Benson, J. and Brown, M. (2007). 'Knowledge workers: what keeps them committed; what turns them away'. Work, Employment and Society, 21: 1, 121-141.

Binyamin, G. and Carmeli, A. (2010). 'Does structuring of human resources management processes enhance employee creativity? The mediating role of psychological availability'. Human Resource Management, 49: 6, 999-1024.

Bonet, R., Cappelli, P. and Hamori, M. (2013). 'Labor market intermediaries and the new paradigm for human resources'. The Academy of Management Annals, 7: 1, 342-392.

Bonetta, L. (2010). 'The postdoc experience: taking a long term view'. Science, 329: 5995, 1091-1098.

Bozeman, B. and Corley, E. (2004). 'Scientists' collaboration strategies: implications for scientific and technical human capital'. Research Policy, 33: 4, 599-616.

Broschak, J.P. and Davis-Blake, A. (2006). 'Mixing standard work and nonstandard deals: the consequences of heterogeneity in employment arrangements'. The Academy of Management Journal, 49: 2, 371-393.

Brown, A.D. (2007). 'Organizational identity', in S. Clegg and J.R. Bailey (eds), International Encyclopedia of Organization Studies, Thousand Oaks, CA: Sage Publications.

Cappelli, P. and Keller, J.R. (2013). 'Classifying work in the new economy'. Academy of Management Review, 38: 4, 575-596.

Charmaz, K. (2003). Strategies of Qualitative Inquiry, Thousand Oaks, CA: Sage Publications. 
Chesbrough, H.W. (2006). Open Business Models. How to Thrive in the New Innovation Landscape, Boston, MA: Harvard Business School Press.

Clinton, M., Totterdell, P. and Wood, S. (2006). 'A grounded theory of portfolio working: experiencing the smallest of small businesses'. International Small Business Journal, 24: 2, 179-203.

Cohen, L., Wilkinson, A., Arnold, J. and Finn, R. (2005). 'Remember I'm the bloody architect!': architects, organizations and discourses of profession'. Work, Employment and Society, 19: 4, 775-796.

Connelly, C.E. and Gallagher, D.G. (2004). 'Emerging trends in contingent work research'. Journal of Management, 30: 6, 959-983.

Cummings, J.N. and Kiesler, S. (2007). 'Coordination costs and project outcomes in multi-university collaborations'. Research Policy, 36: 10, 1620-1634.

Czarniawska, B. and Mazza, C. (2003). 'Consulting as a liminal space'. Human Relations, 56: 3, 267-290.

Davis, G. (2006). 'Improving the postdoctoral experience: an empirical approach', in R. Freeman and D. Goroff (eds), The Science and Engineering Workforce in the United States, Chicago, IL: NBER/University of Chicago Press.

Davis-Blake, A., Broschak, J.P. and George, E. (2003). 'Happy together? How using non-standard workers affects exit, voice, and loyalty among standard employees'. Academy of Management Journal, 46: 4, 475-485.

Delamont, S. and Atkinson, P. (2001). 'Doctoring uncertainty: mastering craft knowledge'. Social Studies of Science, 31: 1, 87-107.

Donnelly, R. (2008). 'Careers and temporal flexibility in the new economy: an Anglo-Dutch comparison of the organisation of consultancy work'. Human Resource Management Journal, 18: 3, 197-215.

Ellis, N. and Ybema, S. (2010). 'Marketing identities: shifting circles of identification in inter-organizational relationships'. Organization Studies, 31: 3, 1-27.

Feldman, D.C. (1984). 'The development and enforcement of group norms'. Academy of Management Review, 9: 1, 47-53.

Fiore, S.M. (2008). 'Interdisciplinarity as teamwork: how the science of teams can inform team science'. Small Group Research, 39: 3, 251-277.

Francis, H. (2003). 'Teamworking and change: managing the contradictions'. Human Resource Management Journal, 13: 3, 71-90.

Gangadharan, L. and Nemes, V. (2009). 'Experimental analysis of risk and uncertainty in provisioning private and public goods'. Economic Inquiry, 47: 1, 146-164.

Garsten, C. (1999). 'Betwixt and between: temporary employees as liminal subjects in flexible organizations'. Organization Studies, 20: 4, 601-617.

George, E. (2003). 'External solutions and internal problems: the effects of employment externalization on internal workers' attitudes'. Organization Science, 14: 4, 386-402.

Gersick, C.J.G. (1988). 'Time and transition in work teams: toward a new model of group development'. Academy of Management Journal, 31: 1, 9-41.

Glaser, B.G. and Strauss, A.L. (1967). The Discovery of Grounded Theory: Strategies for Qualitative Research, Chicago, IL: Aldine Publishing Company.

Guest, D. (2004). 'Flexible employment contracts, the psychological contract and employee outcomes: an analysis and review of the evidence'. International Journal of Management Reviews, 5: 1, 119.

Heusinkveld, S. and Benders, J. (2005). 'Contested commodification: consultancies and their struggle with new concept development'. Human Relations, 58: 3, 283-310.

Jackson, S. and Hong, Y. (2008). 'Knowledge work', in J. Barling and C. Cooper (eds), The SAGE Handbook of Organizational Behavior: Volume One: Micro Approaches, Thousand Oaks, CA: Sage Publications.

Kinnie, N. and Swart, J. (2012). 'Committed to whom? Professional knowledge worker commitment in cross-boundary organizations'. Human Resource Management Journal, 22: 1, 21-38. 
Kniffin, K.M. and Wilson, D.S. (2005). 'Utilities of gossip across organizational levels: multilevel selection, free-riders, and teams'. Human Nature, 16: 3, 278-292.

Koch, G., Füller, J. and Brunswicker, S. (2011). 'Online crowdsourcing in the public sector: how to design open government platforms'. Online Communities, HCII, 6778, 203-212.

Lane, D. and Maxfield, R.R. (2005). 'Ontological uncertainty and innovation'. Journal of Evolutionary Economics, 15: 1, 3-50.

Lee, L.J., Gowers, I., Ellis, L. and Bellantuonoa, I. (2010). 'Well rounded postdoctoral researchers with initiative, who are not always "tied to the bench" are more successful academically'. International Journal for Researcher Development, 1: 4, 269-289.

Lee, M.R. (2014). Leading Virtual Project Teams: Adapting Leadership Theories and Communications Techniques to 21st Century Organizations, Boca Raton, FL: CRC Press.

Lepak, D.P. and Snell, S.A. (2003). 'Managing the human resource architecture for knowledge-based competition', in S. Jackson, M. Hitt, and A. DeNisi (eds), Managing Knowledge for Sustained Competitive Advantage: Designing Strategies for Effective Human Resource Management, Hoboken, NJ: John Wiley \& Sons.

Lind, E.A. and Van den Bos, K. (2002). 'When fairness works: toward a general theory of uncertainty management', in B.M. Straw and R.M. Kramer (eds), Research in Organizational Behavior, Boston, MA: Elsevier.

Mallon, M. and Duberley, J. (2000). 'Managers and professionals in the contingent workforce'. Human Resource Management Journal, 10: 1, 33-47.

Malone, T. (2004). The Future of Work: How the New Order of Business Will Shape Your Organization, Your Management Style and Your Life, Cambridge, MA: Harvard Business School Press.

Marler, J.H., Barringer, M.W. and Milkovich, G.T. (2002). 'Boundaryless and traditional contingent employees: worlds apart'. Journal of Organizational Behavior, 23: 4, 425-453.

Marvis, P. and Hall, D. (1996). 'Psychological success and the boundaryless career', in M.B. Arthur and D.M. Rousseau (eds), The Boundaryless Career: A New Employment Principle for a New Organizational Era, New York: Oxford University Press.

Mathieu, J.E., Heffner, T.S., Goodwin, G.F., Cannon-Bowers, J.A. and Salas, E. (2005). 'Scaling the quality of teammates' mental models: equifinality and normative comparisons'. Journal of Organizational Behavior, 26: 1, 37-56.

Maynard, D.C., Joseph, T.A. and Maynard, A.M. (2006). 'Underemployment, job attitudes, and turnover intentions'. Journal of Organizational Behaviour, 27: 4, 509-536.

McAlpine, L. (2010). 'Fixed-term researchers in the social sciences: passionate investment, yet marginalizing experiences'. International Journal for Academic Development, 15: 3, 229240.

Messick, D.M., Allison, S.T. and Samuelson, C.D. (1988). 'Framing and communication effects on group members' responses to environmental and social uncertainty', in S. Maital (ed.), Applied Behavioral Economics, Vol. II, New York: New York University Press.

Noble, C.H. and Walker, B.A. (1997). 'Exploring the relationships among liminal transitions. Symbolic consumption and the extended self'. Psychology and Marketing, 14: 1, $29-47$.

Osnowitz, D. (2010). Freelancing Expertise: Contract Professionals in the New Economy, Ithaca, NY: ILR Press.

Parker, G.M. (1990). Team Players and Teamwork, San Francisco, CA: Jossey-Bass.

Pfeffer, J. and Baron, J.N. (1988). 'Taking the workers back out: recent trends in the structuring of employment'. Research in Organizational Behavior, 10, 257-303.

Polivka, A.E. and Nardone, T. (1989). 'On the definition of contingent work'. Monthly Labor Review, 112: 4, 9-16.

Quinn, R.P. and Shepard, L.J. (1974). The 1972-73 Quality of Employment Survey. Descriptive Statistics, with Comparison Data from the 1969-70 Survey of Working Conditions, Ann Arbor: Michigan University - Institute for Social Research.

Redpath, L., Hurst, D. and Devine, K. (2009a). 'Contingent knowledge worker challenges'. People and Strategy, 30: 3, 33-38. 
Redpath, L., Hurst, D. and Devine, K. (2009b). 'Knowledge workers, managers, and contingent employment relationships'. Personnel Review, 38: 1, 74-89.

Sampson, E. and St. James, W.D. (2012). 'Mentorship interactions in the aviation or aerospace industries'. Academy of Strategic Management Journal, 11: 2, 35-49.

Scaffidi, A.K. and Berman, J.E. (2011). 'A positive postdoctoral experience is related to quality supervision and career mentoring, collaborations, networking and a nurturing research environment'. High Education, 62: 6, 685-698.

Senior, B. (1997). 'Team roles and team performance: is there "really" a link?' Journal of Occupational and Organizational Psychology, 70: 3, 241-258.

Singer, M. (2004). 'The evolution of postdocs'. Science, 306: 5694, 232.

Swart, J. and Kinnie, N. (2003). 'Sharing knowledge in knowledge-intensive firms'. Human Resource Management Journal, 13: 2, 60-75.

Thau, S., Bennett, R.J., Mitchell, M.S. and Marrs, M.B. (2009). 'How management style moderates the relationship between abusive supervision and workplace deviance: an uncertainty management theory perspective'. Organizational Behavior and Human Decision Processes, 108: 1, 79-92.

Tuckman, B.W. and Jensen, M.A.C. (1977). 'Stages of small-group development revisited'. Group \& Organization Management, 2: 4, 419-427.

Tyler, T.R. and Lind, E.A. (1992). 'A relational model of authority in groups', in M. Zanna (ed.), Advances in Experimental Social Psychology, New York: Academic Press.

Vroom, V.H. (1964). Work and Motivation, New York: Wiley. 